\title{
BOUNDS FOR DETERMINANTS. II ${ }^{1}$
}

\section{J. L. BRENNER}

1. In this article there are derived, for the determinants of certain matrices of (real or complex) constants, lower and upper bounds which are suitable for use with automatic computing machinery.

Let $A=\left(a_{i j}\right)_{1} \ldots n$ be an arbitrary matrix; let $m_{i}$ be the maximum modulus of the elements of the $i$ th row: $m_{i}=\max _{j}\left|a_{i j}\right|$. A lower bound for $\operatorname{det} A$ is given by the relation

$$
|\operatorname{det} A| \geqq\left[1-\sum_{1}^{n} m_{j}\left(\left|a_{i j}\right|+m_{j}\right)^{-1}\right] \prod_{1}^{n}\left(\left|a_{i i}\right|+m_{i}\right) .
$$

A routine can be so programmed that the first factor is computed first; if this factor is negative or 0 , the routine skips the rest of the program. If the first factor is positive, this lower bound is useful especially because of the ease with which the elements of the matrix can be scaled.

It is to be remarked that the bounds of this note apply without formal change not only to the given matrix, but to any other matrix $\left(c_{i j}\right)$ for which the relations $\left|c_{i i}\right|=\left|a_{i i}\right|, \max _{j}\left|c_{i j}\right| \leqq m_{i}$ hold. A single computation gives a bound for a family of matrices.

2. The following abbreviations are used to simplify the typography.

$$
\begin{aligned}
a_{i j}^{\prime} & =a_{i j}-a_{i 1} a_{1 j} / a_{11} \\
m_{i} & =\max _{j \neq 1}\left|a_{i j}\right| . \\
T_{j} & =m_{j}\left(m_{i}+\left|a_{i j}\right|\right)^{-1}, \quad 0\left(0^{-1}\right)=1 . \\
f_{i} & =1-\sum_{1}^{i-1} T_{i}, \quad f_{1}=1, \quad f_{i}^{\prime}=1-\sum_{2}^{i-1} T_{j}^{\prime}, \quad f_{2}^{\prime}=1 . \\
S & =\sum_{1}^{n} T_{i}, \quad S^{\prime}=\sum_{2}^{n} T_{i}^{\prime} .
\end{aligned}
$$

Received by the editors April 11, 1955, and, in revised form, October 26, 1955 and August 4, 1956.

1 The writing of this article was sponsored by the Office of Ordnance Research, contract DA-04-200-ORD-340.

The author acknowledges with thanks the critical reading given this manuscript by Dr. W. J. Firey, Professor P. A. Clement, and the referee. 
(7) $\quad G_{i}=m_{i}\left[T_{i}^{-1}-f_{i}^{-1}\right]$.

Moreover, $m_{i}^{\prime}, T_{j}^{\prime}, G_{i}^{\prime}$ are defined by priming (3), (4), (7) respectively. The bound (1) needs to be established only under the hypothesis $S<1$. The first step is

Lemma 1. If $S<1$, then $S^{\prime}<1$.

Proof. Note $a_{11} \neq 0$ if $S<1$. From (2), (3) the relations

$$
m_{i}^{\prime} \leqq m_{i}\left(1+m_{1} /\left|a_{11}\right|\right), \quad\left|a_{i i}^{\prime}\right| \geqq\left|a_{i i}\right|-m_{1} m_{i} /\left|a_{11}\right|
$$

follow. Hence the following relations are true.

(8)

$$
\begin{aligned}
T_{i}^{\prime} & =1-\frac{\left|a_{i i}^{\prime}\right|}{m_{i}^{\prime}+\left|a_{i i}^{\prime}\right|} \leqq 1-\frac{\left|a_{i i}^{\prime}\right|}{m_{i}\left(1+m_{1} /\left|a_{11}\right|\right)+\left|a_{i i}^{\prime}\right|} \\
& =\frac{m_{i}\left(1+m_{1} /\left|a_{11}\right|\right)}{m_{i}\left(1+m_{1} /\left|a_{11}\right|\right)+\left|a_{i i}^{\prime}\right|} \\
& \leqq\left(1+m_{1} /\left|a_{11}\right|\right) T_{i}=\left(1-T_{1}\right)^{-1} T_{i} .
\end{aligned}
$$

By use of this estimate for $T_{i}$ together with the hypothesis $S<1$ in the form $\sum_{2}^{n} T_{i}<1-T_{1}$, the conclusion

$$
S^{\prime}=\sum_{2}^{n} T_{i} \leqq\left(1-T_{1}\right)^{-1} \sum_{2}^{n} T_{i}<1
$$

follows.

Corollary (Ostrowski [1]). Let $m_{i}, T_{i}, S$ be defined by (3), (4), (6). The hypothesis $S<1$ is enough to establish the conclusion $\operatorname{det} A \neq 0$.

In view of the relation

$$
\operatorname{det} A=a_{11} \operatorname{det} A^{\prime} \text {, }
$$

this is an obvious consequence of Lemma 1.

In attending to the proof of (1), we note first that the right member of (1) can be rewritten $\prod_{1}^{n} G_{i}=\left|a_{11}\right| \cdot \prod_{2}^{n} G_{i}$, and proceed to establish the relations $G_{i}^{\prime} \geqq G_{i}$. The induction hypothesis $\left|\operatorname{det} A^{\prime}\right|$ $\geqq \prod_{2}^{n} G_{i}^{\prime}$ will finish the argument by (9).

\section{Lemma 2. $G_{i}^{\prime} \geqq G_{i}(i>1)$.}

Proof. The explicit assumption $\sum_{1}^{t-1} T_{j}<1$ is made. Without it, (1) is trivial.

We use the estimate (8). Thus we obtain 


$$
\begin{gathered}
f_{i}^{\prime}=1-\sum_{2}^{i-1} T_{j}^{\prime} \geqq 1-\left(1-T_{1}\right)^{-1} \sum_{2}^{i-1} T_{j}=\left(1-T_{1}\right)^{-1} f_{i} ; \\
f_{i}^{\prime-1} \leqq\left(1-T_{1}\right) f_{i}^{-1} .
\end{gathered}
$$

Further, as shown above, $m_{i}^{\prime} \leqq\left(1-T_{1}\right)^{-1} m_{i}$. Next, since $f_{i}^{\prime-1}-1$ is positive, we can obtain

$$
\begin{aligned}
m_{i}^{\prime}-m_{i}^{\prime} f_{i}^{\prime-1} & =-m_{i}^{\prime}\left(f_{i}^{\prime-1}-1\right) \geqq-m_{i}\left(1-T_{1}\right)^{-1}\left[\left(1-T_{1}\right) f_{i}^{-1}-1\right] \\
& =m_{i}\left(1-T_{1}\right)^{-1}-m_{i} f_{i}^{-1} .
\end{aligned}
$$

Thus we can reason as follows

$$
\begin{aligned}
G_{i}^{\prime} & =m_{i}^{\prime}\left[T_{i}^{\prime-1}-f_{i}^{\prime-1}\right] \geqq\left|a_{i i}^{\prime}\right|+m_{i}\left(1-T_{1}\right)^{-1}-m_{i} f_{i}^{-1} \\
& \geqq\left|a_{i i}\right|-m_{i} m_{1} /\left|a_{11}\right|+m_{i}\left(1-T_{1}\right)^{-1}-m_{i} f_{i}^{-1} \\
& =G_{i} .
\end{aligned}
$$

Using similar arguments, the following upper bound for $|\operatorname{det} A|$ can be obtained. It is valid if the hypothesis $S<1$ is satisfied.

$$
|\operatorname{det} A| \leqq \prod_{1}^{n} H_{i}, H_{i}=\left|a_{i i}\right|+m_{i}\left(f_{i}^{-1}-1\right) .
$$

\section{REFERENCE}

1. A. M. Ostrowski, Sur les conditions générales pour la régularité des matrices, Rendiconti di Mat. e delle sue Appl. vol. 10 (1951) pp. 156-168.

State College of Washington,

Aberdeen Proving Ground, and

Stanford RESEARCH Institute 